\title{
Effect of Professional Ethics Workshop on the Moral Intelligence of Prehospital Emergency Personnel in East Azarbaijan, Iran
}

\author{
Sara Ghahremanzadeh Anigh (iD) ${ }^{1}$, Abdolhassan Kazemi (iD) ${ }^{2}$, Saeed Khamnei ${ }^{1}$, Mehran Seif-Farshad (iD) ${ }^{2}$, \\ Firooz Hasanzadeh ${ }^{3}$ and Farzad Rahmani iD ${ }^{4, *}$ \\ 'Tabriz Branch, Islamic Azad University, Tabriz, Iran \\ ${ }^{2}$ Medical Philosophy and History Research Center, Tabriz University of Medical Sciences, Tabriz, Iran \\ ${ }^{3}$ Pre-hospital Emergency and Disaster Management Center, Tabriz University of Medical Sciences, Tabriz, Iran \\ ${ }^{4}$ Emergency Medicine Research Team, Tabriz University of Medical Sciences, Tabriz, Iran \\ "Corresponding author: Emergency Medicine Department, Imam Reza (AS) Medical Research and Training Hospital, Tabriz University of Medical Sciences, Tabriz, Iran. Email: \\ rahmanif@tbzmed.ac.ir
}

Received 2021 June 13; Accepted 2021 December 08.

\begin{abstract}
Background: Moral intelligence is one of the several types of human intelligence. It is the ability to understand right from wrong and behave based on the value which is believed to be right.

Objectives: This study was conducted to evaluate the effect of a professional ethics workshop on the moral intelligence of prehospital emergency technicians in East Azerbaijan Province, Iran, and consequently the improvement of their performance and increase in their work efficiency.

Methods: In this before- and after-interventional study conducted in Tabriz University Prehospital Emergency Center, Iran, in 2020, a total of 234 participants were evaluated. The sample was collected using the Lennick and Kiel's Moral Intelligence Questionnaire and full census method. Before the workshop, the questionnaire was completed by the participants. After the workshop, the same questionnaire was completed again.

Results: The pretest and posttest scores for moral intelligence were $83.02 \pm 7.33$ and $83.49 \pm 8.40$, respectively, which showed a statistically significant difference $(\mathrm{P}<0.05)$. In the three components of moral intelligence, namely consistent behaviors based on principles, values, and beliefs, persistence for the right, and responsibility for personal decisions, there were statistically significant differences $(\mathrm{P}<0.05)$ before and after the workshop.

Conclusions: According to the results, holding a professional ethics workshop was effective in increasing the overall level of moral intelligence, particularly in the three aforementioned components of moral intelligence. It is recommended to continue holding such workshops and improve the conditions and methods of training to increase their efficiency as much as possible.
\end{abstract}

Keywords: Moral Intelligence, Professional Ethics, Emergency Technician, Academic Performance

\section{Background}

Professional ethics is a set of do's and don'ts, value rules, and behavioral tasks that create opportunities for self-improvement and self-control for individuals and organizations (1). Ethical principles protect individuals against problems and help make good decisions to face problems (2). The employees' perception of work ethics also has a significant positive relationship with their occupational satisfaction (3). Implementing professional ethics also has a significant effect on increasing employee commitment and leads to better performance (4). Ethical attitudes can change over time with education (5). Medical ethics is a field that deals with ethical issues related to the medical profession. Furthermore, because emergency technicians work in stressful situations, knowing how to behave toward patients and manage situations is critical for them (6).

Intelligence is defined as the ability to learn from experiences, adapt to shape, and select environments (7). Moral intelligence is one of the several types of intelligence in humans that increases self-efficacy, psychological wellbeing, and learning (8). Moral intelligence is the ability to understand right from wrong and behave based on the value which is believed to be right (9). Moral intelligence consists of 4 main competencies and 10 subsets, including integrity (creating harmony between what we believe and how we behave, doing what is right, and telling the truth), responsibility (taking responsibility for our actions 
and their consequences and admitting mistakes and failures), forgiveness (being aware of one's own and other's shortcomings and mistakes and forgiving oneself and others), and compassion (caring about others which is mutual, meaning that if we are kind and compassionate to others, they will sympathize with us when needed) (10).

Given the numerous corporate ethics scandals and financial crises around the world, what can be done to promote ethical behaviors and prevent similar abuses in the future? Beyond cultural and educational influences, changes depend on how ethical issues are dealt with and how ethical standards are transformed into behaviors. Moral intelligence can help with moral decision-making, social cognition, and self-regulation theory. The basic concepts of this discussion include moral compass, moral commitment, moral sensitivity, moral problem-solving, and moral assertiveness and its basic mechanisms (11). The level of moral intelligence is directly related to organizational behavior and intelligence (12).

\section{Objectives}

According to what has been previously mentioned, it seems that the training issues related to professional ethics and improvement of moral intelligence play an important role in the enhancement of organizational behavior. With this background in mind, this study aimed to evaluate the effect of professional ethics workshops on the level of moral intelligence of prehospital emergency personnel of Tabriz University of Medical Sciences, Tabriz, Iran.

\section{Methods}

\subsection{Study Design, Participants, and Procedure}

This study was a before and after interventional study (pretest-posttest) conducted on prehospital emergency personnel of Prehospital Emergency and Disaster Management Center of Tabriz University of Medical Sciences in 2020. The inclusion criteria included employment in a prehospital emergency center and participation in a professional ethics workshop. The exclusion criteria included not participating in workshops, not filling out any pretest and posttest questionnaires, dissatisfaction with participating in the study, or a history of participation in professional ethics workshops. This study was approved by the ethics code IR.IAU.TABRIZ.REC.1399.008 by the Research Ethics Committee of Islamic Azad University, Tabriz Branch, on May 19, 2020.
The sample was collected by the census, and the final sample size of all prehospital emergency personnel was based on the inclusion and exclusion criteria. After distributing the questionnaires in the workshop, 234 usable questionnaires were collected. A total of 64 samples were not included in the study due to not answering the questions or not filling the pretest or posttest questionnaire.

In this study, the method was explained to the participants before the professional ethics workshop, and then the questionnaires were given to be filled out. Subsequently, the professional ethics workshop was held by the professors of the Ethics Department of the university as a theoretical and practical method based on reference books (13-15). The content of the workshops was in the form of lectures, PowerPoint slides, teaming of participants, presenting the overall results in the teams, questions and answers of the practical workshop, and group discussions, which were planned for 8 hours. About 50\% and 50\% of each workshop were theoretical and practical, respectively. The maximum number of participants in each course of the workshop was 30, and a total of 10 workshops were held. At the end of each workshop, the same moral intelligence questionnaire was presented to the participants and filled out.

\subsection{Moral Intelligence Questionnaire}

The used checklist consisted of two parts; the first part was related to the demographic variables of participants, including age, years of service, gender, marital status, and educational level; the second part included the standard questionnaire of moral intelligence. The Moral Intelligence Questionnaire was developed by Lennick and Kiel in 2005 (10), and the validity and reliability of the Persian version of the Moral Intelligence Questionnaire were confirmed in a study by Siadat et al. in 2009 (16). This questionnaire has 40 items to measure the level of 4 main competencies (ie, integrity, responsibility, forgiveness, and compassion) and 10 subsets, including consistent behaviors based on principles, values, and beliefs, honesty, persisting for the right, keeping the covenant, taking responsibility for personal decisions, acknowledging mistakes and failures, accepting responsibility for serving others, caring for others, and forgiving mistakes of oneself and others (Table 1). For measuring each of the aforementioned subsets, four questions were asked.

Scoring was based on Likert's method, including never (1 point), rarely (2 points), sometimes (3 points), most of the time ( 4 points), and always (5 points). Accordingly, each respondent in each subset (sub-branch) of moral intelligence, which has four items, scored within the range 
of 4 - 20. Moreover, each respondent in a total of 40 items scored within the range of 40 - 200. After calculating the points, to convert them to a maximum of 100 points, the score of each subset (range: 4 - 20) was multiplied by 5, and the total score (range: $40-200$ ) was divided by 2 . The final score of the questionnaire is classified as bad (less than 69), good (70 - 79), very good (80 - 89), and excellent (90 - 100).

\subsection{Statistical Analysis}

The obtained data were analyzed by SPSS software (version 17). Mean \pm standard deviation and frequency (percentage) were used to describe these participants' quantitative and qualitative variables. The Kolmogorov-Smirnov test was used to evaluate the normal distribution of the data. Due to the abnormal distribution of the quantitative data $(\mathrm{P}<0.05)$, the Wilcoxon test was used to compare the data before and after the test. The chi-square was used to compare the qualitative data. In all cases, a P-value less than 0.05 was considered statistically significant.

\section{Results}

This study was performed on 234 participants, including 213 (91\%) male, and the rest were female. The average age of the subjects was $36.93 \pm 7.01$ years, and the average duration of service was $10.70 \pm 5.88$ years. In terms of marriage, 200 (85.5\%) participants were married, and the rest were single. Regarding education level, 110 (47\%) and 105 (44.9\%) participants had a bachelor's degree and a high diploma degree, respectively. The rest of the subjects had a master's degree and PhD.

Table 2 shows the average scores of moral intelligence in different branches and sub-branches before and after the workshop. As observed in Table 2, holding a professional ethics workshop had a statistically significant impact on the components of consistent behaviors based on principles, values, and beliefs ( $\mathrm{P}<0.001)$, persistence for the right $(\mathrm{P}<0.001)$, and taking responsibility for personal decisions $(\mathrm{P}<0.05)$.

Table 3 compares the average scores of moral intelligence in its four main competencies before and after the professional ethics workshop. In Table 3, only in the component of integrity, the professional ethics workshop had a statistically significant difference $(\mathrm{P}<0.001)$, and no statistically significant difference was observed in other components $(\mathrm{P}>0.05)$. The total pretest and posttest scores of moral intelligence were $83.02 \pm 7.33$ and $83.49 \pm 8.40$, respectively $(\mathrm{P}=0.007)$, indicating that holding a professional ethics workshop had a positive and significant effect on the overall level of moral intelligence.

\section{Discussion}

This study evaluated the effect of professional ethics workshops on the level of moral intelligence of prehospital emergency technicians in East Azerbaijan Province. The results showed that holding these workshops was effective in the improvement of some of the components of moral intelligence and made a statistically significant difference in the overall level of moral intelligence.

Moral intelligence is the ability to apply the principles of universal ethics in an individual's goals and interactions. One of the most important moral codes in all cultures is the recognition of responsibility, reciprocity, and the ability to empathize. The majority of religions also share values, such as commitment, responsibility, respect, and dignity to other human beings $(9,17)$. Moral intelligence is tied to emotions and reason, and moral behaviors depend on integrated emotions, intuition, and reasoning. Moral intelligence is what we need to do the right thing and act intelligently (18). The most effective way to transmit and teach ethics is using discussions and ethical practices in specific cases (19).

Although attitudes are considered to be the beliefs and feelings of individuals, moral attitudes can be changed (20). Sims believes that the impact of the ethics course in business on students' thinking and their views on ethical and professional responsibilities and managers' responsibilities in the workplace is high (21). Cannaerts et al. showed that simulated classrooms and laboratories, as safe and practical environments, help nursing students to identify everyday ethical issues (22).

With continuous formal training over time, students' individual and professional values can be changed. Training through formal lectures on professional ethics and more effectively by clinical experiences and modeling the behaviors of professors and medical staff can provide the basis for personal growth and development in the field of professional ethics (23). Based on previous experiences in professional ethics workshops, ethical issues should be addressed comprehensively and explicitly, in which good ethical models are necessary to teach ethical behaviors and standards. The participation of experts and professors who are proficient and very active in ethical values is important because they provide expertise and experience in discussing professional standards and values and emphasize the importance and legitimacy of professional values and ethical standards (24).

Based on the results of the current study, holding professional ethics workshops by university professors and using active training methods, such as group discussions and practical methods, can be effective in improving ethics and 
Ghahremanzadeh Anigh Set al.

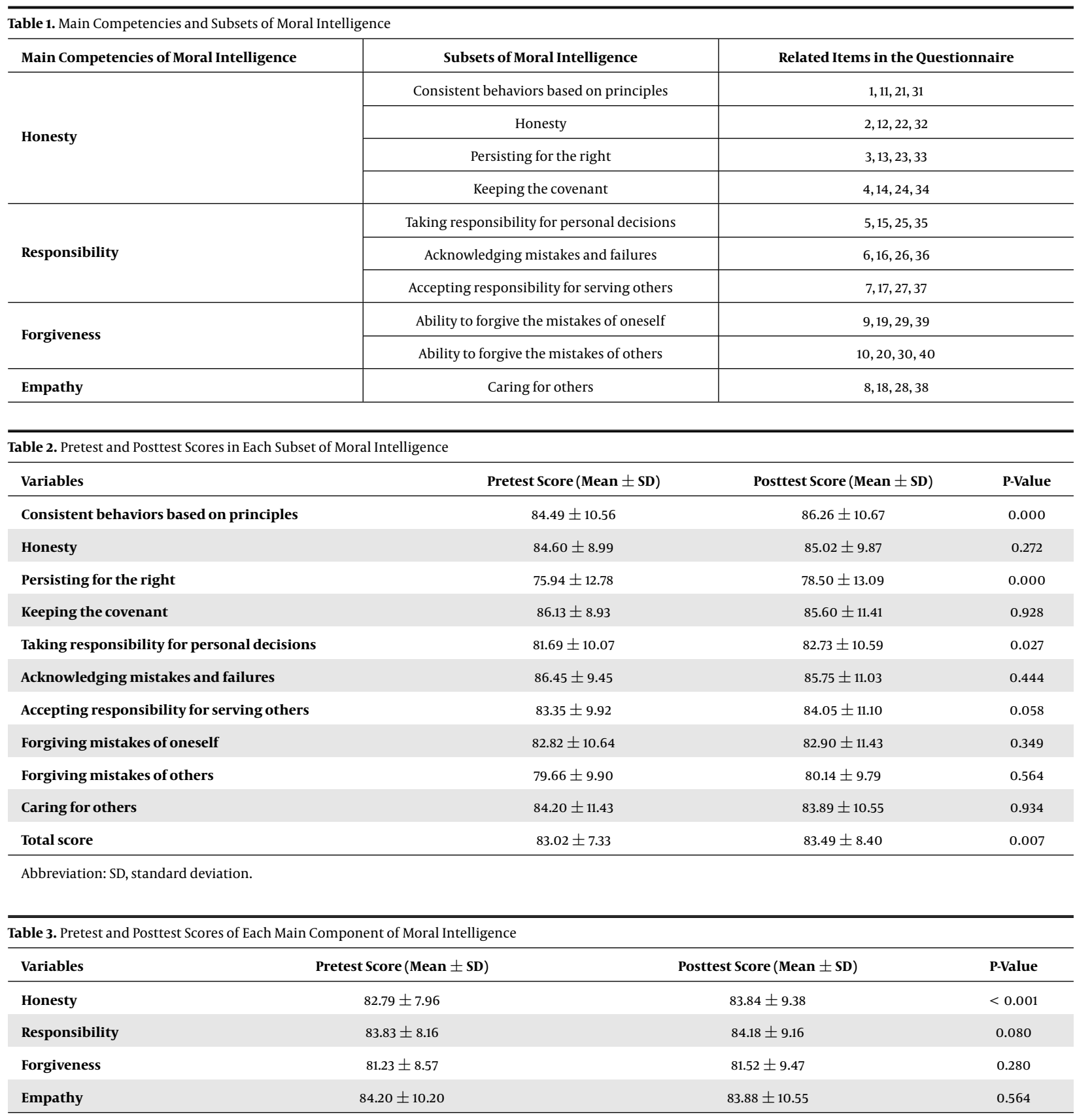

Abbreviation: SD, standard deviation.

moral intelligence. They also can change the ethical attitude toward organizational tasks, assigned responsibilities, and behavior toward clients and patients and provide a basis for participants to improve performance based on professional ethics and acquaintance and discussion on solving professional ethics problems.

\subsection{Limitations}

The limitations of this study included the loss of 64 items of data and a limited number of participants in each workshop. Other limitations were training medical ethics in only one 8-hour workshop session and not long-term follow-up. 


\subsection{Conclusions}

The present study showed that moral intelligence could be developed and promoted, and professional ethics could be taught and learned. Holding professional ethics workshops for prehospital emergency technicians to improve professional ethics performance was effective in some of the characteristics of moral intelligence and increased the overall level of moral intelligence in a positive and significant way. It is recommended to evaluate the effectiveness of this type of study in comparison to other educational programs. It is suggested to perform further studies to examine other methods of professional ethics education and their long-term impacts. It is also recommended to examine other variables affecting moral intelligence, including psychological and personality factors and the impact of the work environment and colleagues on moral intelligence.

\section{Acknowledgments}

The authors would like to express their gratitude to all participants in the study, data collectors, supervisors, and administrative staff of the Prehospital Emergency and Disaster Management Center of Tabriz University of Medical Sciences. This article was written based on the dataset of Sara Ghahremanzadeh's MD thesis entitled "Effect of Professional Ethics Workshop on the Ethical Intelligence of Prehospital Emergency Technicians in East Azerbaijan Province", registered in Tabriz Azad University (no.: 10210101972014).

\section{Footnotes}

Authors' Contribution: All authors met the requirements of the International Committee of Medical Journal Publishers. All authors read and approved the manuscript. SG, AK, SKH, and MS performed data collection, writing, critical revision, and drafting of the manuscript. FR and FH undertook the major parts of the study design and performed the statistical analysis, data analysis, and data interpretation.

Conflict of Interests: The authors declare no conflict of interest.

Ethical Approval: This study was approved by the ethics code IR.IAU.TABRIZ.REC.1399.008 by the Research Ethics Committee of Islamic Azad University, Tabriz Branch, on May 19, 2020.

Funding/Support: There was no funding support for this study.
Informed Consent: In this study, the method was explained to the participants before the professional ethics workshop, and then informed consent sheet forms were given to be filled out.

\section{References}

1. Othman K. Work Ethics and Quality Workplace: An Observation from the Conventional and Islamic Application. Ulum Islam J. 2016;(17):1-19. doi: 10.12816/0029104.

2. Miner M, Petocz A. Moral Theory in Ethical Decision Making: Problems, Clarifications, and Recommendations from a Psychological Perspective. J Bus Ethics. 2003;42(1):11-25. doi: 10.1023/a:1021654015232.

3. Abou Hashish EA. Relationship between ethical work climate and nurses' perception of organizational support, commitment, job satisfaction and turnover intent. Nurs Ethics. 2017;24(2):151-66. doi: 10.1177/0969733015594667. [PubMed: 26260440].

4. Hazizadeh M, Ebrahimpour H. Effect of Moral Intelligence on Employee Performance : Evidence from Ardebil Gas Company. Singapore J Bus Econ Manag Stud. 2015;3(7):129-33. doi: 10.12816/0010968.

5. Emerson TL, Conroy SJ. Have Ethical Attitudes Changed? An Intertemporal Comparison of the Ethical Perceptions of College Students in 1985 and 2001. J Bus Ethics. 2004;50(2):167-76. doi: 10.1023/B:BUSI.0000022126.48574.6e.

6. Jennings B, Arras JD. Ethical Aspects of Public Health Emergency Preparedness and Response. Emergency Ethics: Public Health Preparedness and Response. Oxford University Press; 2016. doi: 10.1093/med/9780190270742.001.0001.

7. Sternberg RJ. Intelligence. Dialogues Clin Neurosci. 2012;14(1):19-27. [PubMed: 22577301]. [PubMed Central: PMC3341646].

8. Alhadabi A, Aldhafri S, Alkharusi H, Al-Harthy I, Alrajhi M, AlBarashdi H. Modelling parenting styles, moral intelligence, academic selfefficacy and learning motivation among adolescents in grades 7-11. Asia Pac J Educ. 2019;39(1):133-53. doi: 10.1080/02188791.2019.1575795.

9. Borba M. Building Moral Intelligence: The Seven Essential Virtues that Teach Kids to Do the Right Thing. Hoboken, New Jersey: Wiley; 2001.

10. Lennick D, Kiel F. Moral Intelligence: Enhancing Business Performance and Leadership Success. Upper Saddle River, New Jersey: Wharton School Publishing; 2005.

11. Tanner C, Moral CM. Intelligence: A Framework for Understanding Moral 32. Competences. Empirically Informed Ethics: Morality between Facts and Norms Library of Ethics and Applied Philosophy. Cham: Springer; 2014.

12. Engelbrecht A, Hendrikz K. Influence of moral intelligence, principled leadership and trust on organisational citizenship behaviour. South Afr J Econ Manag Sci. 2020;23(1):1-9.

13. Shahraki Vahed A, Mardani Hamooleh M, Rezvani F. Professional ethics and regulations in medical emergencies. 3rd ed. Tehran, Iran: Jame-eNegar; 2012.

14. Williams JR. Medical Ethics Manual. 3rd ed. Ferney-Voltaire, France: World Medical Association; 2015.

15. Tsai DF. The WMA medical ethics manual. J Med Ethics. 2006;32(3):163.

16. Siadat S, Kazemi I, Mokhtaripour M. Relationship between moral intelligence and the team leadership in administrators from faculty memberspoint of view at the Medical Sciences University of Isfahan 2008-2009. J Health Admin. 2009;12(36):61-9.

17. McKay R, Whitehouse H. Religion and morality. Psychol Bull. 2015;141(2):447-73.

18. Narvaez D. The emotional foundations of high moral intelligence. New Dir Child Adolesc Dev. 2010;2010(129):77-94. doi: 10.1002/cd.276. [PubMed: 20872605]. 
19. Armstrong MB, Ketz J, Owsen D. Ethics education in accounting: moving toward ethical motivation and ethical behavior. J Account Educ. 2003;21(1):1-16. doi: 10.1016/s0748-5751(02)00017-9.

20. Katz D. The Functional Approach to the Study of Attitudes. Public Opinion Quarterly. 1960;24:163-204. doi:10.1086/266945.

21. Sims RR, Felton EL. Designing and Delivering Business Ethics Teaching and Learning. J Bus Ethics. 2006;63(3):297-312. doi: 10.1007/s10551-0053562-1.

22. Cannaerts N, Gastmans C, de Casterle BD. Response to Commentary.
1: Effectiveness of nursing ethics education: much more research needed. Nurs Ethics. 2014;21(6):743-4. doi: 10.1177/0969733014538907a. [PubMed: 25146156].

23. Kantek F, Kaya A, Gezer N. The effects of nursing education on professional values: A longitudinal study. Nurse Educ Today. 2017;58:43-6. doi: 10.1016/j.nedt.2017.08.004. [PubMed: 28866254].

24. National Academy of Engineering Staff. Emerging Technologies and Ethical Issues in Engineering: Papers from a Workshop. Washington DC, USA: National Academies Press; 2004. 